\title{
Correlation between Radiologic Sign of Lumbar Lordosis and Functional Status in Patients with Chronic Mechanical Low Back Pain
}

\author{
Alireza Ashraf ${ }^{1}$, Siamak Farahangiz ${ }^{2}$, Bita Pakniat Jahromi ${ }^{1,3}$, \\ Nazanin Setayeshpour ${ }^{1}$, Mahshid Naseri ${ }^{1}$, Ali Nasseri ${ }^{2}$ \\ ${ }^{I}$ Department of Physical Medicine and Rehabilitation, Shiraz Burn Research Center, Shiraz University of Medical Sciences, Shiraz, Iran \\ ${ }^{2}$ Department of Radiology, Shiraz University of Medical Sciences, Shiraz, Iran \\ ${ }^{3}$ Shiraz Geriatric Research Center, Shiraz University of Medical Sciences, Shiraz, Iran
}

\begin{abstract}
Study Design: A cross-sectional study.
Purpose: To describe the correlation between lumbar lordosis angle and functional status of patients with chronic mechanical low back pain (CMLBP).

Overview of Literature: There are different and conflicting opinions regarding the relationship between the degree of lumbar lordosis and functional status of patients with low back pain. Nonetheless, the severity of lordosis is still one of the routine physical exams considered in rehabilitation clinics.

Methods: The degree of lumbar lordosis of 150 patients with CMLBP was measured by means of Cobb's method using sagittal standing spinal radiographs. Subjects with probable secondary causes of low back pain (trauma, congenital anomaly, spinal infection, rheumatologic problems and history of spinal surgery) were excluded. Besides recording demographic data, their score of functional disability was estimated using Oswestry Disability Questionnaire, one of the most useful and reliable questionnaires. Comparison between these data was made regarding different age and gender groups.

Results: In this study, 119 subjects were female and 31 male, with an age range of 19-85 years. The average degree of lumbar lordosis was $44.69 \pm 11.43$ and that of Oswestry disability index (ODI) 30.52\%. Although we found a significant direct relationship between age and degree of lumbar lordosis (Pearson's correlation coefficient, $p=0.016, r=0.197$ ), while insignificant correlation was seen between the degree of lumbar lordosis and ODI ( $p=0.129)$.

Conclusions: There was no significant correlation between the degree of lumbar lordosis and the score of functional disability with regards to different age groups and gender.
\end{abstract}

Keywords: Lumbar spine; Low back pain; Lordosis; Disability

\section{Introduction}

Lumbar lordosis is an important factor in decreasing longitudinal stiffness, improvement of muscle movement and control of different mechanical tensions in the lumbar spine, the normal curvature of the lumbar spine

Received Oct 21, 2013; Revised Oct 21, 2013; Accepted Nov 24, 2013

Corresponding author: Mahshid Naseri

Department of Physical Medicine and Rehabilitation, Shahid Faghihi Hospital,

Karimkhan Zand street, Shiraz, 71348-44119, Iran

Tel: +98-07-1123-1904, Fax: +98-07-1123-1904, E-mail: naseri_m@sums.ac.ir 
visible in the sagittal plane [1,2]. Some factors have been suggested to influence its degree as age, gender, race, occupation, weight, height, abdominal and back muscles' strength, lifestyle, physical activity, hormonal factors, deformity of spine, and changes in the inter-spinals discs and sacrum $[2,3]$.

Different studies using various measurement techniques have reported different ranges as normal lumbar lordosis angle: Shayesteh et al. [2] in 2010, using the Winter and Willtse method, found an average of $29.47 \pm 11.90$ degree lumbar lordosisin Iranian population. Youdas et al. [4] and Nourbakhsh et al. [3], using flexible curve method, have already reported the range of $37 \pm 11$ and $37 \pm 13$ degree for lumbar lordosis, respectively. Damasceno et al. [1] used Cobb's angle technique and achieved the value of 62.01 degree in females and 59.30 degree in males and later Milani et al. [5] reported it as 65.4 degree using the same method. Also, the normal average of lordosis has been mentioned about 55 degree (range, 35-80 degree) from T12 spine up to S1 spine in the "Essentials of spinal deformities" textbook [6].

Previous studies have expressed the relationship between the degree of lumbar lordosis and weakness of abdominal muscles as well as tightness of back extensor muscles. Two studies have stood out. Williams et al. [7] recommended that the weakness of these muscles due to prolonged sitting is an important factor in increasing the lordosis angle. This however was later contradicted by Youdas et al. [4]. Also, there are two case reports within this field. One of them studied an 18 year old boy in 2003, and the other a 41-year-old lady in 2009. Both had chronic mechanical low back pain (CMLBP) and abnormal spinal curvature which showed improvement of pain and disability after normalizing the lumbar lordosis by warm up and stabilizer exercise, rehabilitation, and spinal manipulation during a few months [8,9]. Recently, Diab and Moustafa [10] concluded that lumbar extension traction in addition to stretching exercises and infrared radiation can improve the spine sagittal balance parameters including lumbar lordosis, thoracic kyphosis, sacral slope, and positioning of $\mathrm{C} 7$ plumb line and the decrease in the pain and disability in CMLBP. Therefore, changes in lordosis angle may be one of the contributing factors in producing low back pain (LBP) and disability. Further research in this area is necessary because lumbar lordosis curve evaluation still seems to be done as one of the routine physical examinations. This is so as it is based on the concept of its effectiveness in producing LBP and disability which should be addressed in designing the treatment program.

\section{Materials and Methods}

Patients with an age range of 19-85 years and clinical signs and symptoms of mechanical LBP for at least 3 months and referred to our rehabilitation clinics from January 2011 to June 2012 were included in the study. Subjects with secondary causes (Trauma, Congenital anomaly, spinal infection, rheumatologic problems) and those with a history of spinal surgery were excluded. We used simple random sampling method and all the subjects signed an informed consent forms before enrolling in the study. The study protocol was in agreement with the Declaration of Helsinki (October 2008 revision) and was approved by our university ethics committee. For measurement of lumbar lordosis, we used Cobb's angle technique by simple standing lateral lumbar radiographs, including twelfth thoracic spine vertebrae till the first sacral spine vertebrae [11].

To find the angle of lumbar lordosis, the angle between two straight lines drawn tangent to the lower end plate of the twelfth thoracic vertebrae and the upper end plate of the first sacral vertebrae was measured and reported by our radiologist consultant. It is one of the most common techniques in measuring spinal column curvature, and also an easy, fast, and reliable method in clinical evaluations [11-13].

The functional disability was measured by Persian version of Oswestry Disability Questionnaire that is made up of 10 parts: ordinary daily activities like sitting, standing, sleeping, weight lifting, walking, social activities, travelling, sexual activity, self-care, and severity of back pain $[14,15]$.

Each part scored from $0-5$ and the final score was announced in the percentage form: $0-20$, minimal disability; 21-40, moderate disability; 41-60, severe disability; 60-80, crippled; $81-100$, bed ridden.

This questionnaire is one of the most useful instruments in evaluating functional status of patients and its reliability has been proved by different studies $[15,16]$. Statistical methods which were used in this study were $t$-test, Kruskal-Wallis test and Pearson's correlation coefficient. In all statistical analyses, $p<0.05$ was considered significant. 
Table 1. Degree of lumbar lordosis in patients with low back pain in both genders

\begin{tabular}{lccc} 
Gender & Persons & Average & Standard deviation \\
Female & 119 & 44.66 & 11.72 \\
Male & 31 & 44.84 & 10.45 \\
\hline Total & 150 & 44.69 & 11.43 \\
\hline
\end{tabular}

Table 2. Degree of lumbar lordosis in different age groups

\begin{tabular}{lccc} 
Age groups $(\mathrm{yr})$ & Persons & Average & Standard deviation \\
\hline Below 20 & 2 & 41 & 1.41 \\
$21-30$ & 19 & 43.05 & 7.67 \\
$31-40$ & 46 & 43.35 & 11.35 \\
$41-50$ & 51 & 43.76 & 12.44 \\
\hline $51-60$ & 25 & 50.20 & 11.33 \\
Above 60 & 7 & 46.14 & 11.44 \\
\hline Total & 150 & 44.69 & 11.43 \\
\hline
\end{tabular}

\section{Results}

We have recruited 150 patients with CMLBP; 119 females and 31 males. Their age range was $19-85$ years, with average age of $42.14 \pm 11.01$. We could not find any significant correlation between the degree of lumbar lordosis and functional status in patients with CMLBP. Only a significant statistical correlation was seen between age and lumbar lordosis in these subjects.

The degree of lumbar lordosis in our studied population had the range of 5-78 degree with an average of $44.69 \pm 11.43$ degree. The lumbar angle of 107 patients (71.3\%) was within this average range; 23 patients (15.3\%) had lumbar lordosis of more than 56.12 degree, and 20 (13.3\%) had lordosis less than 33.26 degree. In statistical analysis using $t$-test, there was no significant correlation between gender and the degree of lumbar lordosis ( $p=0.937)$ (Table 1).

We divided the patients into 6 age groups, and various parameters were measured separately in each age group. Although there was no significant correlation between age and the degree of lumbar lordosis $(p=0.215)$ in Kruskal-Wallis test, we found a significant direct relationship between age and degree of lumbar lordosis using Pearson's correlation coefficient ( $p=0.016, r=0.197)$ (Table 2).

In statistical analysis by means of Pearson's correlation coefficient, there was no significant correlation between Oswestry Disability Questionnaire (ODQ) score and the degree of lumbar lordosis in general $(p=0.129)$. Also, there was no significant correlation between this score and the degree of lumbar lordosis regarding sex $(p=0.077$ in females, $p=0.611$ in males) and age $(p=0.129)$.

\section{Discussion}

In the present study, although the median degree of lumbar lordosis in females was greater than that of males ( 45 degree and 42 degree, respectively), there was no significant correlation between gender and degree of lumbar lordosis. This result is inconsistent with previous studies such as that by Nourbakhsh et al. [3], which showed that the degree of lumbar lordosis in Iranian females is 10 degrees more than males through investigating both normal subjects and patients with LBP. In another study in 2011 which examined healthy subjects, the degree of lumbar lordosis in females was reported to be 12 degrees more than males [17]. Also, Youdas et al. [18] reported about 6.5 degrees more Standing Lumbar Curvature in women than their male counterparts without current LBP. Thus, our study population including just patients with CMLBP is completely different from the subjects studied in these surveys. Another survey provided about 14 degrees greater lumbar lordosis in females with different categories of LBP than that of males [19]. This report, however, was disapproved by a study in 2011 which did not find any significant difference regarding lumbar lordosis between 
111 women and 87 men with chronic LBP. We observed similar results [20].

With a statistical method, we obtained significant correlation between age and degree of lumbar lordosis. In other words, the degree of lumbar lordosis may increase by aging in patients with CMLBP. This finding supports the results of some studies on healthy subjects such as the research by Damasceno et al. [1]. Furthermore, Kang et al. [21] investigated changes of sagittal spinopelvic parameters in normal Koreans over 50 years old and found no significant difference in lumbar lordosis between different age groups. Indeed, in this regard there are data differences in previous studies. Some authors have concluded that there is no correlation between age and lordosis, while some others have provided contrary results $[3,4,22,23]$.

Although some studies reported different sagittal spinopelvic alignments between patients with CMLBP and healthy subjects (e.g., a survey in 2001 reported lumbar lordosis 4 degrees less in the LBP group [24]), other surveys have provided contradicting results $[20,25,26]$. The degree of lumbar lordosis was not different between normal subjects and patients with LBP in the survey by Mousavi and Nourbakhsh [25] as it suggested the need for reevaluation of the belief about the effects of lumbar lordosis on LBP and treatment programs. The main purpose of our study was to assess the correlation between lumbar lordosis angle and the functional status of patients with CMLBP. From inspection, there are just few articles investigating such correlation. One of them is a study on Turkish coal miners. Authors used ODQ for estimating functional disability score and Cobb's method for identifying the degree of lumbar lordosis and concluded that the change of lordosis is not related to LBP and functional disability. This finding is in the same line with our results but the nature of the coal minors' occupation should be kept in mind as it can affect lumbar curvature [14]. Also, our data support a study in 2003 which was done on 475 elderly females of African American descent with a mean age of 75 years old, indicating that there is no significant correlation between lumbar lordosis and functional disability [27]. We included both men and women between age 19 years and 85 years, with a mean age of 42 years. Therefore, in contrast to the present study, these two main surveys in the field of lumbar lordosis and disability confined their investigation to a particular group of LBP patients. Also, according to the study by Youdas et al. [4] on only 60 patients with chronic LBP, a relatively small percentage, ODQ scores had no significant correlation with the degree of lumbar lordosis in standing. We could provide similar result in a larger sample.

Patients with relative kyphosis in the lumbar spine had significantly more disability-estimated using ODQ-than the patients with normal or lordotic lumbar sagittal Cobb measures according to a study on adult with spinal deformity [28]. On the other hand, one study in 2009 found that L1-S1 lumbar lordosis correlated with walking and standing components of the ODQ as loss of lumbar lordosis was correlated with an increase of pain and decrease of function [29]. Comparing the reports of the last two mentioned articles with our findings might seem irrational due to completely different study samples as they investigated patients with spinal deformity not LBP.

Despite some discrepancies, few authors who studied lumbar lordosis particularly in patients with LBP have found a significant relationship between neither pain severity nor functional status of patients with CMLBP and the magnitude of lumbar lordosis in this population. This may raise many questions about the importance and clinical utility of managing lordosis in this group in order to decrease pain and improve function. We should note that we faced some limitations during this study. First, we didn't have any control group for comparison. Therefore, for better evaluation of the correlation between lumbar lordosis and functional disability, we recommend performing well designed interventional studies investigating lumbar lordosis changes in relation to functional status after therapeutic interventions in patients with LBP. Second, we have to consider the method of lumbar angle measurement, race, and demographic features of the studied population as they can be contributing factors for differences between our results and other studies' reports; also, findings regarding the correlation between demographic data and lumbar lordosis cannot be extended to general population.

\section{Conclusions}

This study did not support the hypothesis that functional disability in patients with CMLBP increases with the change in lumbar lordosis curvature.

\section{Conflict of Interest}

No potential conflict of interest relevant to this article 
was reported.

\section{Acknowledgments}

This study is a part of thesis of Bita Pakniat Jahromi and Nazanin Setayeshpour (no: 2211). Hence, we would like to thank Shiraz University of Medical Sciences for supporting the research.

\section{References}

1. Damasceno LH, Catarin SR, Campos AD, Defino HL. Lordose lombar: estudo dos valores angulares e da participacao dos corpos vertebrais e discos intervertebrais. Acta Ortop Bras 2006;14:193-8.

2. Shayesteh AM, Talebpour F, Alaee A, Hadinejad A, Sajadi M, Nozari A. Association of low back pain with lumbar lordosis and lumbosacral angle. J Mazandaran Univ Med Sci 2010;20:9-15.

3. Nourbakhsh MR, Moussavi SJ, Salavati M. Effects of lifestyle and work-related physical activity on the degree of lumbar lordosis and chronic low back pain in a Middle East population. J Spinal Disord 2001; 14:283-92.

4. Youdas JW, Garrett TR, Egan KS, Therneau TM. Lumbar lordosis and pelvic inclination in adults with chronic low back pain. Phys Ther 2000;80:261-75.

5. Milani GB, Natal Filho A, Amado Joao SM. Correlation between lumbar lordosis angle and degree of gynoid lipodystrophy (cellulite) in asymptomatic women. Clinics (Sao Paulo) 2008;63:503-8.

6. Heary RF, Albert TJ. Spinal deformities: the essentials. New York: Thieme Medical Publishers; 2007.

7. Williams MM, Hawley JA, McKenzie RA, van Wijmen PM. A comparison of the effects of two sitting postures on back and referred pain. Spine (Phila Pa 1976) 1991;16:1185-91.

8. Morningstar MW. Strength gains through lumbar lordosis restoration. J Chiropr Med 2003;2:137-41.

9. Meziat Filho N, Santos S, Rocha RM. Long-term effects of a stabilization exercise therapy for chronic low back pain. Man Ther 2009;14:444-7.

10. Diab AA, Moustafa IM. The efficacy of lumbar extension traction for sagittal alignment in mechanical low back pain: a randomized trial. J Back Musculoskelet Rehabil 2013;26:213-20.

11. Vrtovec T, Pernus F, Likar B. A review of methods for quantitative evaluation of spinal curvature. Eur Spine J 2009;18:593-607.

12. Chen YL. Vertebral centroid measurement of lumbar lordosis compared with the Cobb technique. Spine (Phila Pa 1976) 1999;24:1786-90.

13. Hicks GE, George SZ, Nevitt MA, Cauley JA, Vogt MT. Measurement of lumbar lordosis: inter-rater reliability, minimum detectable change and longitudinal variation. J Spinal Disord Tech 2006;19:501-6.

14. Sarikaya S, Ozdolap S, Gumustass S, Koc U. Low back pain and lumbar angles in Turkish coal miners. Am J Ind Med 2007;50:92-6.

15. Fairbank JC, Pynsent PB. The Oswestry Disability Index. Spine (Phila Pa 1976) 2000;25:2940-52.

16. Mousavi SJ, Parnianpour M, Mehdian H, Montazeri A, Mobini B. The Oswestry Disability Index, the Roland-Morris Disability Questionnaire, and the Quebec Back Pain Disability Scale: translation and validation studies of the Iranian versions. Spine (Phila Pa 1976) 2006;31:E454-9.

17. Lang-Tapia M, Espana-Romero V, Anelo J, Castillo MJ. Differences on spinal curvature in standing position by gender, age and weight status using a noninvasive method. J Appl Biomech 2011;27:143-50.

18. Youdas JW, Hollman JH, Krause DA. The effects of gender, age, and body mass index on standing lumbar curvature in persons without current low back pain. Physiother Theory Pract 2006;22:229-37.

19. Norton BJ, Sahrmann SA, Van Dillen FL. Differences in measurements of lumbar curvature related to gender and low back pain. J Orthop Sports Phys Ther 2004;34:524-34.

20. Chaleat-Valayer E, Mac-Thiong JM, Paquet J, Berthonnaud E, Siani F, Roussouly P. Sagittal spinopelvic alignment in chronic low back pain. Eur Spine J 2011;20 Suppl 5:634-40.

21. Kang KB, Kim YJ, Muzaffar N, Yang JH, Kim YB, Yeo ED. Changes of Sagittal Spinopelvic Parameters in Normal Koreans with Age over 50. Asian Spine J 2010;4:96-101.

22. Murrie VL, Dixon AK, Hollingworth W, Wilson H, Doyle TA. Lumbar lordosis: study of patients with and without low back pain. Clin Anat 2003;16:144-7.

23. Tuzun C, Yorulmaz I, Cindas A, Vatan S. Low back pain and posture. Clin Rheumatol 1999;18:308-12.

24. Tsuji T, Matsuyama Y, Sato K, Hasegawa Y, Yimin Y, Iwata $\mathrm{H}$. Epidemiology of low back pain in the el- 
derly: correlation with lumbar lordosis. J Orthop Sci 2001;6307-11.

25. Mousavi SJ, Nourbakhsh MR. Lumbar lordosis in asymptomatic subjects and patients with chronic low back pain. J Res Med Sci 2003;8:61-4.

26. Ng JK, Richardson CA, Kippers V, Parnianpour M. Comparison of lumbar range of movement and lumbar lordosis in back pain patients and matched controls. J Rehabil Med 2002;34:109-13.

27. George SZ, Hicks GE, Nevitt MA, Cauley JA, Vogt MT. The relationship between lumbar lordosis and radiologic variables and lumbar lordosis and clinical variables in elderly, African-American women. J Spinal Disord Tech 2003;16:200-6.

28. Glassman SD, Bridwell K, Dimar JR, Horton W, Berven S, Schwab F. The impact of positive sagittal balance in adult spinal deformity. Spine (Phila Pa 1976) 2005;30:2024-9.

29. Lafage V, Schwab F, Patel A, Hawkinson N, Farcy JP. Pelvic tilt and truncal inclination: two key radiographic parameters in the setting of adults with spinal deformity. Spine (Phila Pa 1976) 2009;34:E599606. 